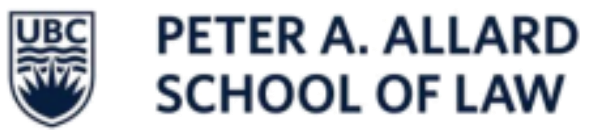

THE UNIVERSITY OF BRITISH COLUMBIA

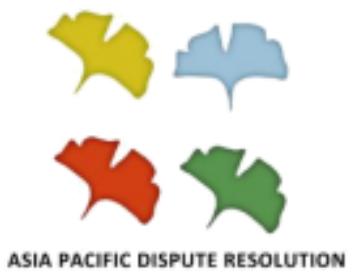

\title{
Public Health and Drug Policing in Malaysia: Using Empirical Evidence for Advocacy
}

\author{
Fifa Rahman \\ Malaysian AIDS Council \\ Iqa Mohd Salleh \\ Center of Excellence for Research in AIDS \\ Olga Golichenko \\ International HIV/AIDS Alliance
}

\author{
Karsten Lunze \\ Boston University School of Medicine
}

APDR Working Paper Series

Volume 3 Number 1

ISSN 2371-6304

by CC) (i) (9) Fifa Rahman et al., 2016.

This article is made available as part of the Asia Pacific Dispute Resolution Working Paper Series and is licensed under a Creative Commons Attribution-NonCommercialNoDerivatives 4.0 International License (CC-BY-NC-ND) 


\title{
PUBLIC HEALTH AND DRUG POLICING IN MALAYSIA: USING EMPIRICAL EVIDENCE FOR ADVOCACY 1
}

\author{
Fifa Rahman \\ Malaysian AIDS Council \\ Iqa Mohd Salleh \\ Center of Excellence for Research in AIDS \\ Olga Golichenko \\ International HIV/AIDS Alliance \\ Karsten Lunze \\ Boston University School of Medicine
}

\section{Introduction}

After declaring a "War on Drugs" in 2003, Malaysia adopted harm reduction as official policy in 2006 to reduce substance use related risks and subsequently implemented needle-andsyringe exchange programs and methadone maintenance therapies. Seven years after the inception of Malaysia's harm reduction policy, the Centre of Excellence and Research in AIDS (CERiA) and the Malaysian AIDS Council (MAC) carried out qualitative research with police officers and people who use drugs to determine attitudes towards harm reduction and drug use, and to elicit perspectives on better approaches in drug law enforcement.

We conducted qualitative research with 20 people who use drugs and 11 police officers based in police stations in various states in Malaysia (Kuala Lumpur, Pahang, and Kelantan). These interviews showed that police often lack understanding on the efficacy and operation of harm reduction programs. Interviews with people who use drugs pointed to a host of police practices that constitute barriers to treatment, including physical violence and psychological abuse, corrupt practices and failure to inform individuals of their rights. These results will inform subsequent

\footnotetext{
${ }^{1}$ The work on which this paper is based was supported by funding from the Dutch government under the Community Action on Harm Reduction and the European Union funded Asia Action on Harm Reduction provided to FR/MAC.

The contents of this publication are the sole responsibility of the authors and do not necessarily reflect the opinion of the European Union.
} 
quantitative surveys to generate further evidence on drug law enforcement and public health implications in Malaysia.

Based on these empirical findings, we undertook evidence-based advocacy, maintaining an advocacy log containing key events including meetings with key officials, tweets, emails and text messages that contributed to improving police awareness about harm reduction and drug evidence-based drug policy. This chapter summarizes our approach to and results of evidenceinformed advocacy work.

Our experience of this qualitative research and its gains for advocacy demonstrate that larger scale interventions involving high-level police officials may be necessary to change policing practices, some of which are structural or are ingrained in police culture but oppose public health evidence. Numerous studies and reports have proven that harsh penalties and oppressive policing negatively impact public health, increase marginalisation, and increase drug-related crime, and that the inverse i.e. decriminalisation paired with access to voluntary health services improve public health and reduce drug-related crime. (Hughes \& Stevens, 2012; Fullerton, et al, 2014; GCDP, 2014; Rhodes, et al, 2006) Negative practices have the potential to seep (and in some cases, are already seeping) into other agencies in drug policy and drug control. A consolidated written drug policy would assist in mitigating these issues, as we outline below.

\section{Background}

Drug policy in Southeast Asia is characterised by criminalization of drug use, including incarceration for drug use and possession, corporal punishment, compulsory detention for substance use and even capital punishment for major drug offences. These punitive policies, enforced in many countries in the region, co-exist with state-endorsed harm reduction and health services, presenting an apparent policy conflict. Budgets for drug control, however, continue to be predominantly dedicated towards drug supply and demand reduction law enforcement activities. These activities include arresting people who use drugs and low-level drug couriers, judicial corporal punishment, compulsory drug detention, and surveillance at borders.

In Malaysia, harm reduction was adopted for the first time in 2006 following a concentrated epidemic of HIV among persons who inject drugs, with the government rolling out needle-andsyringe exchange programs and methadone maintenance therapies. Today these programs continue, along with criminalisation of drug use (incarceration, corporal punishment, and police surveillance post-release from incarceration). The former, which seeks to reduce harms resulting from drug use and connect individuals to treatment and welfare services, is counterproductive and counterintuitive to the latter, which seeks to punish them for drug use.

A quote from Johann Hari illustrates this: 'Our laws are built around the belief that drug addicts need to be punished to stop them. But if pain and trauma and isolation cause addiction, then 
inflicting more pain and trauma and isolation is not going to solve that addiction. It's actually going to deepen it.' (Aitkenhead, 2015)

In 2003, Malaysia declared a "Year of Total War on Drugs" (Reid et al, 2007). Yet by 2011, the National Anti-Drugs Agency announced that it would phase out compulsory drug rehabilitation centres and convert them into voluntary outpatient treatment centres called Cure \& Care centres. This was likely due to the fact that compulsory drug detention centres (called 'Pusat Serenti' or PUSPEN) had up to $90 \%$ relapse rates. (Reid, et al, 2007) At time of writing, 18 out of 28 compulsory rehabilitation centres remain operational. All of them have been rebranded as Cure \& Care Rehabilitation Centres (CCRCs) but with only seven providing methadone treatment (AADK 2013). The other ten CCRCs continue to provide abstinence-based services as well as a range of other treatments with unproven efficacy ( $\mathrm{Fu}$, et al, 2012). It should be noted that these latter institutions are different from the newly transformed Cure and Care Service Centres (CCSCs) that promote offering methadone treatment for walk-in clients who voluntarily request it, in addition to psychosocial support and counselling.

In 2006, only three years later after the declaration of "War on Drugs", needle-and-syringe programs were introduced in three states in Malaysia. Needle and syringe exchange programs implemented initially by non-government organizations were expanded to Ministry of Health clinics in later years (Degenhardt, et al, 2014). Despite of the adoption of treatment to address Malaysia's drug problem, arrests for possession and use of drugs continued to increase, as illustrated in Figure 1, and similar patterns for drug seizures have been reported (Singh, et al, 2013).

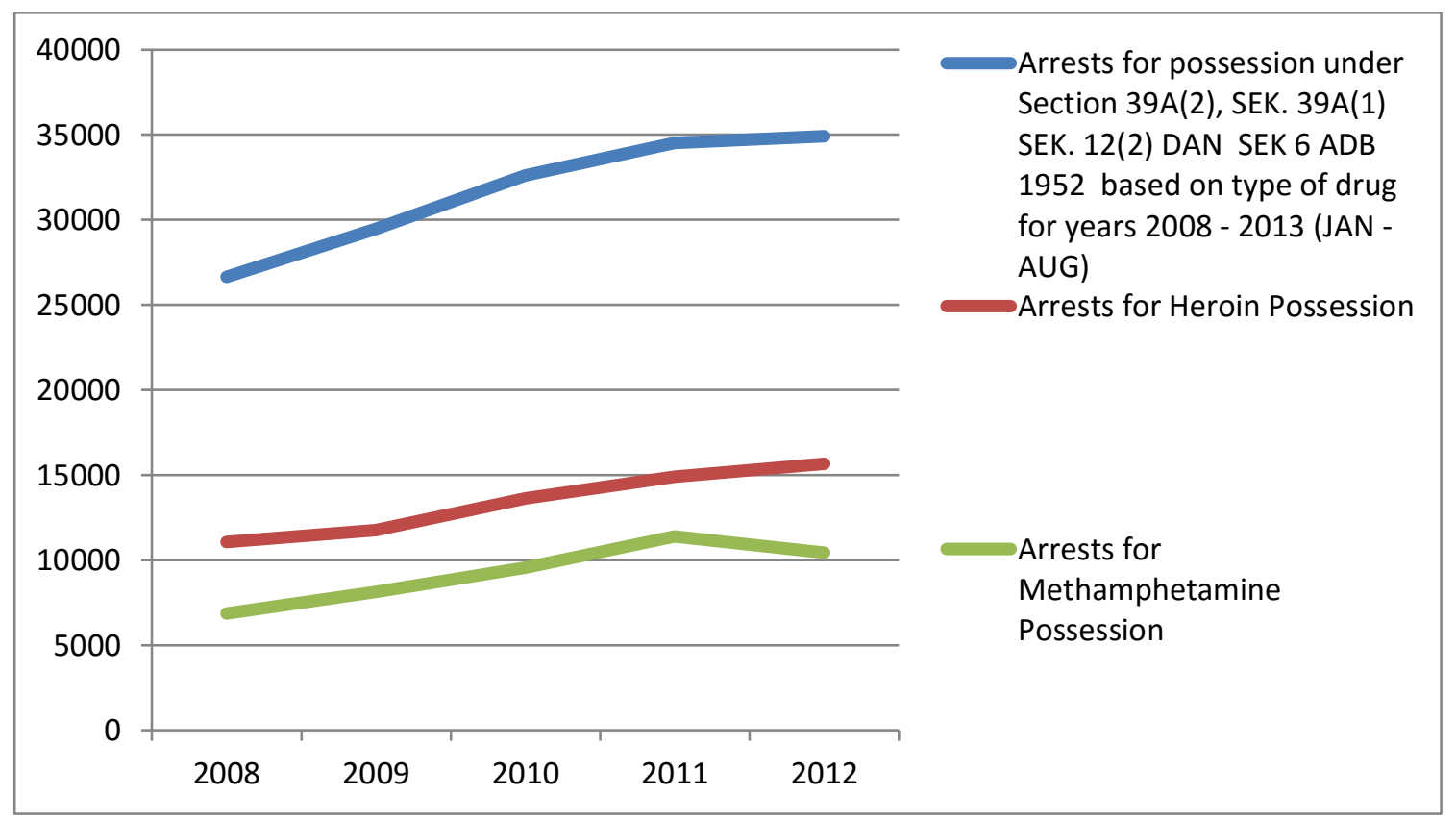

Figure 1: Arrests for possession and use of drugs in Malaysia, 2008-2012. Source: Narcotic Crimes Investigation Department, Royal Malaysian Police, 2013 
It is estimated that currently 170,000 people who inject drugs live in Malaysia, with 60 percent of opioid injecting drug users also reporting lifetime use of stimulants, e.g., amphetamine-type substances (Singh, et al, 2013). Past studies have shown that policing activities have resulted in negative consequences on health care seeking of/by people who use drugs, including reluctance to access health services (Small, et al, 2006; Maher, et al, 2006), actual reduction in access to health services (Wood, et al, 2003), an increase in drug-related violence (Werb, et al, 2011) and displacement of drug markets to other locations (Small, et al, 2006). Punitive policing has been shown to increase risky drug use behaviour such as needle sharing and adverse health outcomes such as drug overdoses (Lunze, et al, 2014). A previous survey we conducted among 53 police officers in Malaysia found that slightly more than half of the respondents said that they would seize needles and syringes provided by government-endorsed needle and syringe exchange programs, whether or not an arrest was made (Rahman and Parasuraman, 2012).

In many places, including Malaysia, aggressive policing of drug users continues as police tend to perceive drug users as a problem 'because of their involvement in crime and other anti-social behaviours' (Lister, et al, 2008 at 15). The stigma surrounding drug use has prevented harm reduction efforts to reduce transmissions of infectious diseases from becoming a priority. Optimizing HIV prevention among people who inject drugs in many resource-constrained countries is hampered by drug control policies that fail to distinguish between drug use and risk of HIV infection (Vlahov, et al, 2010). Fitzgerald (2005 at 203) describes policing of this nature to be a 'public health menace'.

Crofts, et al (2013) consider the cultural milieus of police practices, and how practices are passed down to younger generations of police. The relationship between police and drug users is complex because there is an intertwined market economy between police, drug traffickers and users. Narcotics operations are often planned taking into account the possibility and estimated volume of bribes. Officers often target street drug users because they are perceived as the main cause of acquisitive crimes (such as petty thefts) and violent crimes (such as street robberies) (Crofts, et al, 2013). Reasons for detention range from having positive urine test results and possession of illicit drugs as classified by the Dangerous Drug Act (1952) (WHO, 2009). Where police and harm reduction services coexist and where police are expected to both arrest drug users and support harm reduction measures, 'perceived and often severe conflict' continues. (Crofts, et al, 2013 at 5.18).

The lack of published studies on drug policing and its implications for harm reduction in Malaysia motivated us to examine opinions and attitudes among police and drug users on drug law enforcement practices, consequences for harm reduction, related implications for public health, and health implications for drug users. We also aimed to explore policing procedures and potential human rights implications. Our goal was to generate empirical evidence about the main 
challenges and issues faced by people who use drugs when interacting with police, so that these issues can be addressed through advocacy.

In this article, we share our evidence-based approach to advocacy work in the Asia Action Project. Funded by the European Union, this project enables civil society advocates in China, India, Malaysia, Indonesia, Cambodia and Vietnam to advocate for evidence-based interventions in drug policy, including harm reduction. Civil society advocates identified key issues or barriers in the local environment and formulated them as 'advocacy asks' - i.e. key goals to address via awareness programs and direct advocacy with stakeholders and policymakers.

\section{Interview Methodology}

In 2013, the Malaysian AIDS Council reviewed existing evidence and challenges faced by drug users in Malaysia and identified the following "advocacy asks" for the Asia Action Project. First, is to achieve the availability of doctors and health staff in police custody for people who use drugs. Second, is the reduction of criminal sanctions in relation to drug use and to achieve progress towards the formulation of a written integrated drug policy that includes health and harm reduction measures.

To address existing evidence gaps and generate evidence for our advocacy work with the police, we conducted semi-structured qualitative interviews with a purposive sample of police officers of varying rank and position, in Malaysian states chosen because we had anecdotal evidence of progressive, less repressive police practice (Pahang), highest HIV infection rates among injecting drug users (Kelantan) and highest prevalence of drug use (Kuala Lumpur).

To address existing knowledge gaps and generate evidence for our advocacy work with the police, we conducted semi-structured qualitative interviews with a sample of Malaysian police officers in these three states. These officers were selected based on their willingness to participate and their ability to provide information on drug policing.

In the same three states, we interviewed 20 people who use drugs with a different semistructured qualitative instrument. Inclusion criterion was drug use in the past 30 days. Study participants were interviewed at centres providing needle-and-syringe exchange services. They were aged between 20-47 years. Most reported polydrug use, mostly heroin and stimulants. Results of this qualitative research have been informing our advocacy work.

\section{Results of the study}

Our police interviews are consistent with existing literature (Singh, et al, 2013; Rhodes, et al, 2006) which convey that there are many accounts of tensions between police attitudes and 
practices, and harm reduction approaches. It emerged from these interviews that police lack understanding on the efficacy and operation of harm reduction programs. They also expressed incredulity at the possibility of a drug free ASEAN. Drug user interviews pointed to a host of police practices that constitute barriers to treatment, including abuse, corruptive practices, and failure to inform of rights. Many officers lack an understanding of the principles and efficacy of antagonist treatment for opioid dependence. These treatments include methadone and buprenorphine treatments.

All of the police officers expressed scepticism in regard to the ASEAN target of a drugs-free region by 2015 and the similar vision for Malaysia. This might reflect some sentience about the enormity of the task at hand of controlling drug use in Malaysia, and that arrests alone might not be efficient in reducing or eliminating drug use. People who use drugs interviewed in this study related bitter experiences related to key performance indicators that need to be achieved by police officers as part as their job requirement.

In academic literature, police officers have been noted to have negative perceptions of drug users, including that they have 'inherent criminal potential' (Rhodes, et al, 2006) and that they are uninterested in positive change. Our results confirm these findings. Understanding the perspective of PWUD and police officers allowed us to target our advocacy strategies to the lived experiences of the key stakeholders involved. Collaborating internationally with groups in other countries with similar research and advocacy interests, this research also sets directions for further inquiries.

\section{Evidence-based advocacy}

Following this research, during the year 2013, the Malaysian AIDS Council conducted a series of advocacy activities to promote evidence-based policy in policing relating to people who use drugs. Some examples of these activities included a workshop with mid-level police on police leadership in public health, and a roundtable on drug law reform held at the Malaysian Parliament house.

One of the tools we are using for capturing data about on-going work and perceived progress is the advocacy log (Golichenko \& Sibanda, 2013). This allows advocates to keep a record of the notable events, advocacy targets and results arising from these events. It makes it possible to assess projects' perceived contribution to the key moments of policy change. In Malaysia, work has been focused around the following advocacy asks:

Advocacy ask 1: availability of doctors and health staff in police custody 
Reforming the law enforcement response entails coordination with public health aims. A key strategy to achieve that goal is to scale up meaningful interaction between police and public health officials and advocates, so the two sides can familiarize each other with their operational environments. Examples are the access of medical providers to the pre-trial detention setting (known as police 'lockups' in Malaysia), or the promotion and scale-up of voluntary and evidence-based drug treatment. While police training has in the past been useful for improving police knowledge of harm reduction, rarely does this knowledge translate into practice. Because Malaysia does not have a written drug policy consolidating activities and procedures of all agencies, and merely punitive drug laws, practice on harm reduction and health is consistently in a state of flux, dependent upon the tenures of certain bureaucrats and the whims and fancies of another.

The Malaysian AIDS Council has used various policy and advocacy efforts towards these goals. In October 2013, we undertook a visit to a police 'lockup' in Jinjang, a suburb of Kuala Lumpur where there are high levels of drug use and crime. This key event led to the drafting of a paper proposing a pilot project for medicines in police custody, which took about three weeks (including incorporation of input from expert consultants).

Another significant event in our advocacy work involved attending the UN Commission on Narcotic Drugs session in Vienna in March 2014. As is customary, the government delegation was led by the Deputy Minister of Home Affairs, the Honourable Wan Junaidi Tuanku Jaafar. Fifa Rahman attended the meeting with support from the Asia Action project. After initial introductions, a meeting followed between the Deputy Minister and the former President of Switzerland Ruth Dreifuss, who sits on the board of Global Commission on Drug Policy, an organization that is against punitive and ineffective drug policy. Madame Dreifuss lauded the Cure \& Care voluntary centres, and emphasised the need for medicine provision in police custody. She enquired as to the reasons why this was not yet in place and a discussion took place, which indicated the Deputy Minister's pro-health stance. During the discussion, Fifa Rahman mentioned that she had prepared the proposal on a pilot project in Jinjang police custody centre mentioned above. The Deputy Minister then requested that the proposal be submitted to him upon our return to Malaysia.

While the proposal was submitted to the Deputy Minister on 11 April 2014, it became clear that in addition to high-level advocacy, it was necessary to closely engage implementing police officers and achieve consensus on health services in police lockups.

On 24 October 2014 and 4 November 2014, consultations were held with officers in charge of police stations (OCSs) and officers in charge of police districts (OCPDs) in the states of Kuala Lumpur and Johor, respectively. Out of 171 police officers interviewed, 97\% agreed or strongly agreed that doctors should be employed within the police force for work in lockups. 


\section{Advocacy ask on reduction of criminal sanctions in relation to drug use}

A focus on law enforcement goals that ignores harm reduction aims is a major threat to access to essential medicines in police custody and other harm reduction services. In early 2014, a core group of activists began a series of advocacy efforts with high-level officials and politicians towards the production of a written drug policy. On 11 April 2014, Fifa Rahman and Sarah Iqbal from the Malaysian AIDS Council and Professors Adeeba Kamarulzaman and Rusli Ismail from the Centre of Excellence for Research in AIDS met with the Deputy Minister of Home Affairs Wan Junaidi Tuanku Jaafar, and discussed developments in Malaysian drug policy that were detrimental to public health. He indicated support for voluntary Cure \& Care treatment centres, and said that so long as he was Minister they would remain open. However, in subsequent meetings with the acting Law Minister Nancy Shukri and acting Human Rights Minister Paul Low, and we found that while there was substantial political support for voluntary methadone services and the need for medication in police custody, some bureaucrats were adamant about advancing punitive measures.

In mid-2014, Malaysian AIDS Council responded to a shift towards arrests and detention in joint operations by the National Anti-Drugs Agency and the Royal Malaysian Police. We have anecdotal evidence that this is negatively affecting voluntary enrolment into methadone programs. It appears that the result of such law enforcement measures is a growing deficit in trust between police and drug users. Edland-Gyrt and Skatvet (2013) comment that the need to develop such trust, if taken seriously, will positively impact access to drug treatment services. The Malaysian AIDS Council and its partners continue to work to emphasise the importance of measures to build trust in relation to harm reduction and health, but are cautious of emerging conflicting rhetoric indicating discrepancies between public statements and actual commitments. For example, while there is high-level assurance that methadone maintenance therapy will continue, public statements indicate the strengthening of arrest collaborations between the National Anti-Drugs Agency (AADK) and the Royal Malaysian Police.

On 2 June 2014, our team, composed of Fifa Rahman, Professors Kamarulzaman and Ismail, as well as former High Court Judge Rahim Uda, met with the Minister of Home Affairs Zahid Hamidi. National Anti-Drug Agency top-level management were present. In our presentations to the Minister and the Agency officials we emphasised that investments in harm reduction in Malaysia had been proven to be cost effective (World Bank, 2013) and that enrolment in methadone programs has been shown to reduce crime among enrolled clients (Fullerton, et al, 2014; Kamarulzaman, 2013). Mr. Uda stated that in his years as a High Court judge sentencing people to the mandatory death penalty for drugs, he realised that he was not really sanctioning the drug kingpins, but rather persons of low socioeconomic background who had been recruited as couriers. The Minister decided that workshops were needed to produce a written drug policy.

These discussions culminated in a 3-day drug policy drafting workshop on 13-15 January 2015, during which stakeholders in Malaysian drug policy were divided into 6 clusters, including harm 
reduction cluster and the law cluster. This three day workshop brought together more than 70 stakeholders including the National Anti-Drugs Agency, the Royal Malaysian Police, civil society representatives including Malaysian AIDS Council and Pengasih (an NGO operating therapeutic community modalities) and academic research centres such as the Centre of Excellence for Research in AIDS (CERiA) under the University of Malaya, and the Drug Research Centre under University Sains Malaysia. Numerous recommendations came out of the 6 clusters. While 1 cluster maintained that a drug-free ASEAN was possible, the other 5 clusters recommended the abolition of judicial corporal punishment for drug use, the scaling up of harm reduction services, and the abolition of 2-year supervision (including random urine testing) for persons never convicted of crime.

\section{Conclusion}

The results from the qualitative research highlight connections between policing involved in enforcing drug-related laws and human rights implications of such actions. Police are driven into high-pressure situations where they are forced to conduct ineffective, but institutionallyendorsed strategies to achieve their target of eliminating drug use. For example, police are often expected to arrest persons who use drugs instead of facilitating their rehabilitation by directing them to addiction care services.

We therefore recommend that key performance indicators geared towards public health and development aims be introduced into policing work, such as the number of people who might have been subject to arrest but are instead channelled towards health services. Drugs policing indicators on the whole should be refocused towards concentrating on offenses relating to largescale trafficking and supply.

Harm reduction in Malaysia is gradually being scaled up and has been proven to be costeffective. Scaling-up implementation has led to a three-fold increase in the number of needle and syringe exchange programs nationally since the initiative began (World Bank, 2013). National HIV prevalence among new injecting drug users is projected to decline from 11 percent in 2011 to 10 percent in 2015 (Ministry of Health, 2012), indicating that prevention programs such as needle and syringe exchange and methadone maintenance therapy are effective preventive measures.

As outlined above, harm reduction policies by health authorities coexist with arrests and raids by law enforcement agencies. These different goals are in conflict but coexist as elements of national drug policy. Civil society organisations have been stepping up efforts, supported by the Ministry of Health and the National Anti-Drugs Agency, to scale-up harm reduction services while increasing awareness of these programs. However, misconceptions about the nature of these programs act as barriers to such initiatives and hamper their effectiveness. A key misconception is the belief that needle and syringe exchange programs encourage or increase 
drug use, despite numerous studies that have shown that such measures do not result in increase in drug use among clients (and Junge, 1998) and instead play a positive role in terms of connecting drug users with health workers. Of note, police arrests do not reduce drug use among PWUD (Lunze, 2014). In fact, exchange programs have been proven to be a key medium to reach out to populations that have limited access to health services (Volkow, 2004).

Many academics consider law a social determinant of health (Burris, 2010). Policy that is constant in flux and dependent upon whims and fancies instead of evidence-based policy is counterproductive to public health. In contrast, a written drug policy incorporating elements of harm reduction, policing, psychosocial interventions and public health will mitigate and eventually remedy negative impacts in drug treatment, HIV prevention, and improving social outcomes related to reductions in drug use. As such, this chapter recommends that governments make an effort to consolidate health and enforcement in a single written drug policy, clearly specifying roles of agencies and taking into account existing evidence. Such a measure can address conflicts between police and NGOs serving PWUD, while improving public health of key affected populations.

\section{Bibliography}

Aitkenhead, Decca, 'Johann Hari: 'I failed badly. When you harm people, you should shut up, go away and reflect on what happened' (2 January 2015) The Guardian

http://www.theguardian.com/media/2015/jan/02/johann-hari-interview-drugs-book-independent

Agensi Anti-Dadah Kebangsaan (AADK)/National Anti Drugs Agency

http://public.adk.gov.my/direktori/cnc1m.php / (Accessed 29 May 2014)

Burris, S. 2011. Law in a social determinants strategy: a public health law research perspective. Public Health Reports 126 (Suppl 3): 22-27

Crofts, N. et al. 2013. Law enforcement and drug policy in Southeast Asia. In Drug Law Reform in East and Southeast Asia, ed. F. Rahman et al. Lexington Books.

Degenhardt, L et al. 2014. What has been achieved in HIV prevention, treatment and care for people who inject drugs, 2010-2012? A review of the six highest burden countries. International Journal of Drug Policy 25(1): 53-60

Edland-Gyrt, Marit, and Astrid Helene-Skatvedt. 2013. Thresholds in a low-threshold setting: An 
empirical study of barriers in a centre for people with drug problems and mental health disorders. International Journal of Drug Policy 24(3): 257-264

Fitzgerald, J.L. 2005. Policing as public health menace in the policy struggles over public injecting. International Journal of Drug Policy 16(4): 203-206

Fu, J.J. et al. 2012. Absence of antiretroviral therapy and other tisk factors for morbidity and mortality in Malaysian compulsory drug detention and rehabilitation centers. PloS one, 7(9): e44249

Fullerton, C.A. et al. 2014. Medication-assisted treatment with methadone: assessing the evidence. Psychiatric Services 65(2): 146-157

GCDP (Global Commission on Drug Policy), 'Taking Control: Pathways to Drug Policy that Works' (September 2014)

Golichenko, Olga and Ethel Sibanda. 2013. Policies on drug use and HIV: baseline results of "Asia Action on Harm Reduction" programme. Paper presented at International Congress on AIDS in Asia and the Pacific, Bangkok, Thailand, November 2013.

Hughes, Caitlin Elizabeth and Alex Stevens, 'A resounding success or a disastrous failure: Reexamining the interpretation of evidence on the Portuguese decriminalisation of illicit drugs' (2012) 31 Drug and Alcohol Review 101-113

Lunze K, Raj A, Cheng DM, Quinn EK, Bridden C, Blokhina E, Walley AY, Krupitsky E, Samet JH. Punitive policing and associated substance use risks among HIV-positive people in Russia who inject drugs. Journal of the International AIDS Society 2014 Jul 9;17(1):19043.

Maher, L., Coupland, H., \& Musson, R. 2007. Scaling up HIV treatment, care and support for injecting drug users in Vietnam. International Journal of Drug Policy, 18(4): 296-305

Malaysian Ministry of Health, HIV/STI Section. 2012. Malaysia 2012 Global AIDS Response, Country Progress Report. Reporting Period: January 2010 to December 2011. Kuala Lumpur.

Lister, S., et al. 2008. Street Policing of Problem Drug Users. York: Joseph Rowntree Foundation. 
Rahman, Fifa and Guganesan Parasuraman. 2012. Police knowledge of needle-and-syringe programs and harm reduction in Malaysia. Paper presented at the 6th International Society for the Study of Drug Policy (ISSDP) Conference, Canterbury Cathedral Lodge, Canterbury, Kent, United Kingdom, 30-31 May 2012.

Reid, G., Kamarulzaman, A. \& Sran, S.K, 'Malaysia and harm reduction: the challenges and responses.' (2007) 18(2) International Journal of Drug Policy 136-140

Rhodes, T. et al. 2006. Street policing, injecting drug use and harm reduction in a Russian City: A qualitative study of police perspectives. Journal of Urban Health 83(5): 911-925

Singh, D., Chawarski, M. C., Schottenfeld, R., \& Vicknasingam, B. 2013. Substance abuse and the HIV situation in Malaysia. Journal of Food and Drug Analysis 21(4), s46-s51

Small, W. et al. 2006. Impacts of intensified police activity on injection drug users: evidence from an ethnographic investigation. International Journal of Drug Policy 17(2): 85-95

Vlahov, D., \& Junge, B. 1998. The role of needle exchange program in HIV prevention. Public Health Reports 113 (Suppl 1): 75-80.

Vlahov, D., Robertson A.M., \& Strathdee, S.A. 2010. Prevention of HIV Infection among injection drug users in resource-limited settings. Clinical infectious diseases 50 (suppl 3): s114s121

Volkow, Nora, Director, US National Institute on Drug Abuse, correspondence with Allan Clear, "NIH Response on Harm Reduction and Needle Exchange," Aug. 4, 2004.** http://www.drugwarfacts.org/cms/syringe exchange\#sthash.aVgNLejJ.eHCYmu6w.dpuf

Werb, Dan, Greg Rowell, Gordon Guyatt, Thomas Kerr, Julio Montaner, and Evan Wood, Effect of Drug Law Enforcement on Drug-Related Violence: a Systematic Review (2011) 22(2) International Journal of Drug Policy 87-94

Werb, D. et al. 2011. Effect of drug law enforcement on drug-related violence: A systematic review. International Journal of Drug Policy 22(2): 87-94

Wood, E. et al. 2003. The impact of a police presence on access to needle exchange programs. JAIDS Journal of Acquired Immune Deficiency Syndromes 34(1): 116-117 
World Bank, Return on Investment and Cost-Effectiveness of Harm Reduction Programmes in Malaysia (2013).

World Health Organization (WHO), Assessment of compulsory treatment of people who use drugs in Cambodia, China, Malaysia and Vietnam: An Application of selected human rights principles (2009). 